\title{
La batería de San Francisco de Paula de la plaza de San Juan de Puerto Rico: análisis del modelo arquitectónico, siglos XVIII Y XIX
}

\begin{abstract}
The Battery of San Francisco de Paula on Plaza de San Juan, Puerto Rico: Analysis of its typology, $I 8^{\text {th }}$ and $19^{\text {th }}$ centuries
\end{abstract}

DOI: https://doi.org/IO.22380/20274688.1774

Recibido: 27 de octubre del 2020

Aprobado: 3 de marzo del 2021
NURIA HINAREJOS MARTÍN*

Universidad Complutense de Madrid nuriahinarejos@ucm.es

\section{R E S U M E N}

El objeto de este artículo es contribuir a la aportación de una información detallada acerca de la batería de San Francisco de Paula, fortificación construida en el lado sureste de la ciudad de San Juan de Puerto Rico, para evitar posibles desembarcos enemigos en este sector. Son muy pocos los autores que mencionan esta obra y se desconoce el momento exacto de su construcción, aunque varias fuentes gráficas y documentales localizadas en el Archivo General Militar de Madrid, el

* Premio de Defensa 2019 por su tesis doctoral “El sistema de defensas de Puerto Rico (1493-1898)". Doctora en Historia del Arte de la Universidad Complutense de Madrid; licenciada en Historia del Arte, máster en Estudios Avanzados en Historia del Arte Español, máster en Formación del Profesorado de la misma universidad y diplomada en Turismo de la Universidad de Salamanca. Ha realizado varias estancias de investigación en la Universidad de Puerto Rico y una estancia docente en la Universidad Nacional Autónoma de México (UNAM) en el 2021. Ha participado en varios congresos nacionales e internacionales, en instituciones como: la Universidad de Puerto Rico, la Universidad Iberoamericana, el Centro de Estudios Avanzados del Caribe, National Park Service, la Casa de España de San Juan de Puerto Rico, la Facultad de Arquitectura de la Unam y el Instituto de Historia y Cultura Militar, entre otras, sobre varios de los ingenieros militares que trabajaron en el sistema de defensas construido en la isla durante los siglos XVIII y XIX. Orcid: https://orcid.org/0000-000I-7949-2543 
Archivo Histórico Nacional y el Archivo General de Puerto Rico, analizadas para este estudio, permiten constatar que fue levantada a finales del siglo xviII por el ingeniero militar, de origen español, Juan Francisco Mestre.

Palabras clave: batería de San Francisco de Paula, San Juan de Puerto Rico, fortificaciones del Caribe, ingenieros del siglo xvII, Juan Francisco Mestre

\section{$\begin{array}{llllllll}\mathbf{A} & \mathbf{B} & \mathbf{S} & \mathbf{T} & \mathbf{R} & \mathbf{A} & \mathbf{C} & \mathbf{T}\end{array}$}

The purpose of this article is to contribute to clarify information about the San Francisco de Paula battery, built in the south of the city of San Juan of Puerto Rico. The aim of this fort was to avoid a possible enemy disembarkation. Apart from being mentioned by few authors, the exact moment of the construction of this fortification is not well-known. However, the graphic and documentary sources analyzed for this study confirm that it was erected at the end of the $18^{\text {th }}$ century by the Spanish-born military engineer, Juan Francisco Mestre.

Keywords: San Francisco de Paula Fort, San Juan de Puerto Rico, Caribbean's fortifications, Juan Francisco Mestre, $18^{\text {th }}$ century

\section{Introducción}

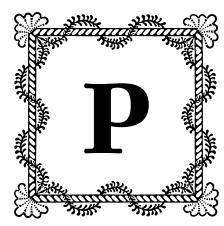

uerto Rico es la isla más oriental y la de menor extensión de las Antillas Mayores. Se encuentra situada al este de la República Dominicana, originalmente conocida como la isla de La Española. Tiene forma cuadrangular y cuenta con una superficie de 9 I04 $\mathrm{km}^{2}$, incluyendo la isla de mayor tamaño conocida con el topónimo indígena de Borinquén, actual Puerto Rico, y otras más pequeñas situadas a poca distancia de ella: Vieques y Culebra al este, Caja de Muertos y Cardona al sur, Mona y Desecho al oeste y la isla de Cabras frente a la bahía de San Juan. Fue descubierta por Cristóbal Colón en noviembre de 1493 durante su segundo viaje al continente americano. Desde mediados del siglo Xvi se convirtió en una de las posesiones espańolas más importantes del Caribe, debido a las ventajas que ofrecía la bahía y el puerto de San Juan, capital de la isla, características que la convirtieron en escala de la Carrera de Indias y en una plaza de gran valor estratégico en el Caribe (Zapatero, "San Juan de Puerto Rico" 39).

El dominio de las Indias Occidentales convirtió a la Corona española en una de las monarquías más poderosas de Europa durante la Edad Moderna, lo que despertó el interés y la codicia de las principales potencias europeas. Ello 
obligó a invertir grandes recursos en la construcción de un complejo sistema defensivo en los principales puertos de ultramar. La ciudad de San Juan comenzó a fortificarse a mediados del siglo XVI mediante la construcción de varias obras defensivas, siguiendo el modelo de la arquitectura militar renacentista italiana, fundamentada en la edificación de construcciones armónicas, equilibradas, funcionales, monumentales y de trazado geométrico, cuyas obras fueron financiadas por los situados procedentes del Virreinato de Nueva España (Cruz de Arrigoitia 35; Marchena 26I-310).

La primera obra defensiva levantada en Puerto Rico fue una casa-fuerte construida por el primer gobernador de la isla, Juan Ponce de León, a comienzos del año 1509 en la villa de Caparra, cuyas obras se prolongaron durante un periodo de cinco o seis meses, con el objetivo de proteger a las tropas españolas de posibles ataques enemigos y almacenar en ella todas las armas y municiones de guerra. A partir de ese momento se construyeron varias obras defensivas: Casa Blanca, para alojar en ella a la familia de Juan Ponce de León tras abandonar la villa de Caparra; la fortaleza de Santa Catalina, destinada a evitar posibles desembarcos en la bahía de San Juan; los puentes de San Antonio y Martín Peña sobre los caños del mismo nombre, para facilitar el paso de caballos y el acarreo de materiales para la construcción de las nuevas defensas de la ciudad, y en 1540 se levantó una torre almenada de mampostería de planta circular en el promontorio del Morro, con el fin de completar y mejorar el sistema de defensas construido hasta el momento en la capital.

Este primitivo torreón se convirtió en el castillo de San Felipe del Morro con la llegada a la isla del maestre de campo Juan de Tejada y el ingeniero italiano Bautista Antonelli en 1589 (Hinarejos, El sistema de defensas 5I ss.). La defensa de la ciudad de San Juan quedó reforzada mediante la construcción de varias baterías costeras como el fuerte del Boquerón, situado a unos $15 \mathrm{~km}$ de la capital, y la batería del Escambrón, cuya finalidad era evitar el paso de posibles lanchas enemigas a la laguna de Condado y a las inmediaciones del puente de San Antonio.

En el siglo xvir se levantó el fuerte de San Juan de la Cruz, más conocido como El Cañuelo, en la isla de Cabras, para evitar posibles desembarcos en la bahía y el puerto de San Juan. Se construyó una muralla terraplenada, realizada en mampostería, piedra arenisca y caliza, revistada con un mortero de arena y cal, con muros de 7,5 $\mathrm{m}$ de alto, reforzada con troneras de unos $7 \mathrm{~m}$ de espesor en la parte más alta y más de una docena de baluartes defendidos con artillería, con el objetivo de defender todos sus flancos mediante la obtención de un 
fuego cruzado, siguiendo las máximas de la arquitectura militar abaluartada. De manera paralela a la construcción del recinto amurallado, se edificó el fuerte de San Cristóbal, un pequeño reducto hecho en mampostería con parapetos a barbeta, levantado sobre un promontorio situado a unos $50 \mathrm{~m}$ sobre el nivel del mar, para defender el frente de tierra de la ciudad de posibles ataques.

A mediados de aquella centuria se reforzó la defensa del lado norte de la ciudad mediante la construcción de la batería de La Perla, una fortificación mencionada tan solo de pasada por algunos autores que trataron el tema. Varias fuentes gráficas y documentales custodiadas en diferentes archivos españoles muestran que fue una fortificación erigida sobre una punta escarpada de difícil acceso, situada a casi I km de distancia del castillo de San Cristóbal. Tenía forma de baluarte cerrado por su gola, estaba defendida por una sencilla muralla en forma de hornabeque con parapetos a barbeta, dotada de un cuerpo de guardia capaz de alojar hasta ocho soldados, un pequeño aljibe y varias piezas de artillería (Hinarejos, "La batería de La Perla" 39-78).

La historiografía que trata la historia de Puerto Rico y el sistema de defensas construido por la Corona española en la isla para defenderla de posibles ataques, es muy amplia. Las primeras noticias que se conocen sobre Puerto Rico provienen de los cronistas de los siglos XVI y XVII, entre los que destacaron Francisco López de Gomara, Gonzalo Fernández de Oviedo, John Layfiel, Juan López de Velasco y John Laet, entre otros. La información aportada por estos cronistas fue completada por varios autores del Siglo de las Luces como Abbad y Lasierra, cuya obra es considerada la más importante de aquel momento porque permite conocer el estado en el que se encontraba la isla tras un reconocimiento realizado por este monje benedictino en el año 1772 .

Las descripciones y los documentos analizados por los cronistas del siglo XVI al XVIII fueron fundamentales para la labor realizada por los historiadores posteriores, entre los que destacaron Pedro Tomás de Córdova, Cayetano Coll y Toste e historiadores del arte de reconocido prestigio como Diego Angulo Íńiguez, entre otros, aunque, sin duda, los estudios más importantes sobre el sistema defensivo de Puerto Rico fueron llevados a cabo por Adolfo de Hostos y Juan Manuel Zapatero. Ambos historiadores fueron coetáneos, tuvieron una formación en Historia y ejercieron la carrera militar.

La labor de investigación hecha por los numerosos historiadores que trataron el sistema de defensas construido por la monarquía hispana en Puerto Rico muestra que estas construcciones no se ciñeron a un plan previo de fortificación. El complejo sistema defensivo proyectado en la isla quedó concluido tras un 
periodo de casi cuatro siglos, durante los cuales se construyeron nuevas obras defensivas y se reformaron las existentes, como consecuencia del mal estado en el que se encontraban, los desperfectos ocasionados por el clima y las fuertes lluvias del Caribe, los asedios sufridos en la isla y la evolución experimentada en la artillería. A estos factores se unieron la falta de recursos económicos, mano de obra especializada e ingenieros formados, que obligaron a la Corona a invertir importantes recursos económicos, lo cual ocasionó la prolongación en el tiempo de estas construcciones.

El objeto de este artículo es contribuir a la aportación de una información detallada acerca de la batería de San Francisco de Paula, fortificación erigida en el lado sureste de la ciudad de San Juan, capital de la isla, para evitar posibles desembarcos enemigos y reforzar la defensa de este sector de la ciudad, la cual, ha pasado inadvertida para la mayoría de los expertos en la materia. Muy pocos autores mencionan esta obra defensiva y desconocemos el momento exacto de su construcción, pero diferentes fuentes gráficas y documentales, localizadas en varios archivos españoles, analizadas para este estudio permiten datar su construcción a finales del siglo xviıI y constatan que fue diseñada por el ingeniero militar Juan Francisco Mestre, con el fin de reforzar el sistema de defensas diseñado por el mariscal de campo Alejandro O'Reilly, cuyas obras fueron dirigidas por el ingeniero irlandés Tomás O’Daly, con el objetivo de convertir la ciudad de San Juan en una plaza inexpugnable.

Varios planos localizados en el Archivo General Militar de Madrid, desconocidos hasta la fecha, y los informes elaborados por varios ingenieros militares que trabajaron en la construcción del sistema defensivo de la isla, contribuyen al conocimiento de la obra. Esta documentación permite analizar el proceso constructivo de la fortificación, conocer las características arquitectónicas de su fábrica y las obras de mejora y reparación realizadas en el siglo XIX.

\section{El sistema defensivo de Puerto Rico en el siglo XviII}

En el siglo XVIII se construyeron nuevas fortificaciones y se reformaron las existentes, como consecuencia de la evolución experimentada en la artillería, lo cual tuvo como resultado lo que Juan Manuel Zapatero denominó el "periodo de mayor esplendor de las fortificaciones puertorriqueñas”, ya que las tensiones mantenidas con Francia, Inglaterra y Holanda obligaron a construir un 
complejo sistema defensivo en la isla ante la posibilidad de sufrir nuevos ataques (Zapatero, "El periodo de esplendor"; Zapatero, "La plaza porticada”; Zapatero, "Las fortificaciones históricas"). En ese momento se desarrolló la arquitectura militar abaluartada, un modelo defensivo aplicado en las fortificaciones espańolas, francesas, holandesas, italianas y suecas, basado en la construcción de fortificaciones geométricas, regulares, simétricas, uniformes y bien proporcionadas en todas sus partes ${ }^{\mathrm{I}}$.

Estas nuevas obras defensivas fueron erigidas con muros de sillería en forma de talud y de menor altura que las construcciones realizadas durante la etapa anterior, ya que el objetivo era minimizar en ellas los impactos de la artillería, y su defensa se reforzó mediante la apertura de cañoneras y troneras defendidas por varias piezas de artillería y numerosas defensas exteriores destinadas a dificultar los ataques enemigos.

Tras la toma de Portobelo (Panamá) en I739, el asedio a Cartagena de Indias en I74I y la toma de La Habana por los ingleses en agosto de I762, Carlos III vio la imperiosa necesidad de reforzar y modernizar los sistemas defensivos de todos los territorios de ultramar. Entre otras muchas acciones programadas para la América hispana, el monarca envió a las Antillas Mayores y en concreto a la isla de Puerto Rico, a casi un centenar de ingenieros militares durante el siglo XVIII, para supervisar, proyectar, construir nuevas obras defensivas y reparar algunas de las existentes que se encontraban en estado ruinoso.

En relación con esta situación y el papel que debieron asumir los ingenieros de la Corona, en 176r el monarca envió a la isla al ingeniero irlandés Tomás O’Daly para conocer el estado en el que se encontraba la ciudad de San Juan²,

I Sébastien Le Pestre de Vauban (1639-1707) fue el ingeniero más representativo de la fortificación abaluartada que trabajó al servicio de las coronas francesa y española durante esta centuria. Construyó numerosas obras defensivas en Francia, aunque su mayor aportación fue la publicación de $\mathrm{La}$ defensa de las plazas, tratado traducido al castellano por Ignacio Sala y editado por Pedro Gómez de Requena en la ciudad de Cádiz (1743). Esta obra tuvo una importante repercusión en todos los territorios de la monarquía hispana, ya que los modelos defensivos planteados en ella fueron construidos en muchas plazas de la Península y ultramar (Zapatero, "Síntesis histórica”; Blanes 62-73).

2 Tomás O'Daly nació hacia el año 1730 en el condado de Guativay (Irlanda), fruto del matrimonio de Demetrio O’Daly y Juana Blake. El 9 de agosto de 1744 ingresó al Regimiento de Ultonia con el grado de alférez, el 14 de marzo de 1747 fue ascendido a teniente y un año después participó en la defensa de la plaza de Génova. Se formó en la Academia de Matemáticas de Barcelona, fue ascendido a ingeniero extraordinario ( 4 de julio de $175 \mathrm{I}$ ), ingeniero ordinario ( 22 de septiembre de 1756), capitán (I de octubre de 1756), teniente coronel e ingeniero segundo (IO de febrero de 176I) y coronel (Io de mayo de 1773). Participó en varias obras de ingeniería en la península ibérica hasta 
proyectar y dirigir la construcción de nuevas obras defensivas (Hinarejos, "El ingeniero Tomás O’Daly"; Hinarejos, "Estado de las defensas"). El 8 de abril de 1765 desembarcó en la isla el mariscal de campo Alejandro O’Reilly, acompañado de tres sargentos mayores, ocho ayudantes y un teniente, que habían trabajado con él en La Habana, con el fin de realizar un nuevo reconocimiento de la capital y proyectar la construcción de nuevas obras defensivas.

Durante el mes que permaneció en la isla, elaboró un informe acerca del sistema económico, político y social de Puerto Rico y redactó un estudio tácticoestratégico de la capital con el fin de convertir a la ciudad de San Juan en una plaza inexpugnable, como consecuencia de su importancia estratégica en el Caribe. La construcción de las primeras defensas proyectadas por O’Reilly comenzó el I. ${ }^{\circ}$ de enero de $\mathbf{1 7 6 6}$, bajo la dirección del ingeniero jefe de las Reales Obras de Fortificación, Tomás O’Daly. Junto a él destacó la presencia de Juan Francisco Mestre ${ }^{3}$, ingeniero de origen español, que trabajó bajo su mando en la construcción del sistema defensivo de la isla, convirtiéndose en su sucesor tras su fallecimiento, ocurrido el I9 de enero de 178r (Hinarejos, "La intervención del ingeniero").

Durante los casi treinta ańos que Juan Francisco Mestre permaneció en la isla, realizó una gran labor como ingeniero tracista y el I3 de septiembre de 1783 elaboró un proyecto defensivo basado en la idea de retrasar un posible ataque en la capital, cuyos costes ascendieron a 26392 pesos, 5 reales y 27 maravedís (AGI, 25IO), e informó de la necesidad de limpiar el puerto para evitar bancos de arena en la bahía y el puerto de San Juan. Asimismo, realizó varias obras de mejora en la fortaleza de Santa Catalina e hizo varias reparaciones en el fuerte

que en 176r fue destinado a Puerto Rico donde trabajó hasta el i9 de enero de I78I cuando falleció (Agms, I.\%/O-97; AGI, Sección de Contratación, sig. 5505, n. . 1, ramo 32; Castro, Arquitectura I00; Capel et al. 350).

3 Nació en Alburquerque (Extremadura) hacia 1732, fruto del matrimonio del teniente del Regimiento de Mallorca Quirce Mestre y Ana Rodríguez Carrasco. Ingresó al regimiento de su padre el I de diciembre de 1749 y el 8 de mayo de 1753 fue ascendido a alférez. Se formó en la Academia de Matemáticas de Barcelona y en enero de 1757 fue nombrado ingeniero delineador. Trabajó como ingeniero ayudante en la ciudad de Cartagena (España), labor por la que es posible pensar que fuera ascendido a teniente e ingeniero extraordinario el 22 de julio de 1760 y a capitán e ingeniero ordinario el I2 de julio de 1765 , momento en el que fue enviado a Puerto Rico. Durante su estancia en la isla fue ascendido en varias ocasiones: teniente coronel ( 6 de julio de 1776 ), ingeniero segundo ( 25 de enero de 1778 ), coronel e ingeniero jefe ( 18 de julio de 1778 ), ingeniero director ( 26 de noviembre de 1793). Dos años después de regresar a España obtuvo el grado de brigadier (4 de septiembre de 1795) (AGS, SGU, leg. 3793, caja 2, f. 69; SGU, leg. 5837, caja I, f. 37; SGU, leg. 5837, caja 2, f. 26; SGU, leg. 5837, caja 4, f. I8; SGU, leg. 3794, caja I, f. 6 y SGU, leg. 5837, caja 5, f. I3; AGMS, I. ${ }^{2}$ M-3057; AGI, Santo_Domingo, 2304, 2308; Castro, Arquitectura 70-7I). 
de San Juan de la Cruz, más conocido como El Cañuelo, valoradas en 3229,4 pesos y 29 maravedís (AGI, Santo_Domingo, 2310) ${ }^{4}$.

Mestre también propuso construir diferentes baterías provisionales en las inmediaciones del castillo de San Jerónimo del Boquerón'; proyectó la construcción de doce apostaderos erigidos sobre un terreno sólido de barro gredoso, situado entre el canal de San Jorge y el puente de San Antonio, para evitar posibles desembarcos, cuya defensa reforzó mediante la construcción de tres líneas defensivas formadas por cortinas de mampostería y sillería con sus correspondientes fosos; construyó varias defensas exteriores en el castillo de San Cristóbal ${ }^{6}$, conocidas como los fuertes del Abanico, La Princesa y Santa Teresa, con el fin de neutralizar un posible desembarco en el lado norte de la ciudad, entre otras muchas obras (Hinarejos, "El sistema de defensas" IO7-I36).

\section{La batería de San Francisco de Paula: características arquitectónicas}

Esta fortificación ha sido mencionada, tan solo de pasada, por autores como Pedro Tomás de Córdova, Adolfo de Hostos, Bibiano Torres Ramírez, María de los Ángeles Castro, Milagros Flores Román y Héctor Andrés Negroni, algunos de

4 Pequeño fortín de madera de planta cuadrada construido en la isla de Cabras para reforzar la defensa de la bahía y el puerto de San Juan y obtener un fuego cruzado con la artillería emplazada en la fortaleza de Santa Catalina. Quedó prácticamente arruinado durante el ataque holandés de I625 protagonizado por Balduino Enrico, lo que obligó al gobernador y capitán general de la isla, Gabriel de Rojas, a reedificarlo a mediados del siglo Xviı, lo que dio como resultado un pequeño fuerte de mampostería de planta cuadrada con muros almenados sin flancos, de aproximadamente I5 $\mathrm{m}$ de lado y unos 4,5 $\mathrm{m}$ de alto, capaz de alojar hasta 16 piezas de artillería, dotado de un aljibe $\mathrm{y}$ dos pequeños almacenes de municiones y pertrechos de guerra a prueba de bombas (Hostos I8I).

5 Pequeño fortín de madera de planta cuadrada erigido a finales del siglo xvi sobre un peñasco de roca arenisca en la punta de Cangrejos, situada a unos $15 \mathrm{~km}$ de la capital. Esta fortificación fue de vital importancia durante el ataque británico sufrido en la isla en 1595 al mando del pirata sir Francis Drake, momento en el que quedó prácticamente arruinado. Estas circunstancias obligaron a reconstruirlo en mampostería a comienzos de la centuria siguiente (Alegría 173).

6 A mediados del siglo xvir se construyó el recinto amurallado de la capital y el lado oriental de la plaza se reforzó con el fuerte de San Cristóbal. Fue un pequeño reducto de mampostería con parapetos a barbeta, levantado sobre un promontorio situado a unos $50 \mathrm{~m}$ sobre el nivel del mar, para defender el frente de tierra de la ciudad. Esta primitiva fortificación fue ampliada y modificada en el siglo XVIII, convirtiéndose en una de las principales defensas de la capital y uno de los modelos más notables de arquitectura abaluartada construida por la Corona española en Ultramar (R. Torres 3-37). 
los cuales dataron su construcción en el año i796. La mayoría de ellos afirma que fue construida por el gobernador Ramón de Castro y sus obras se prolongaron hasta el gobierno de Toribio de Montes, con el objetivo de reforzar la defensa del lado sur de la ciudad, aumentar la efectividad de la artillería emplazada en el fuerte de San Jerónimo del Boquerón mediante la obtención de un fuego cruzado, siguiendo las máximas de la arquitectura militar abaluartada, y cerrar el camino que comunicaba la puerta de San Justo con el área de Puerta de Tierra — situado en el lado oriental de la ciudad, a las afueras del recinto amurallado-, ante la posibilidad de sufrir un inminente ataque británico (Córdova 7I; Hostos 193).

Los autores que mencionan esta obra no se refieren a ella con la misma tipología arquitectónica, ya que suele aparecer citada como batería o fuerte de San Francisco de Paula, pero si tenemos en cuenta que ambas construcciones son defensas exteriores, defendidas por artillería, cuya finalidad era proteger un lienzo de muralla o la cortina de un fuerte, cualquiera de estos términos podría ser utilizado para referirse a ella ${ }^{7}$.

Un documento localizado en el Archivo General Militar de Madrid, desconocido hasta la fecha, permite constatar que el 5 de marzo de 1793 el gobernador y capitán general de la isla, Francisco Torralbo, organizó una reunión en la fortaleza de Santa Catalina, a la que acudieron los hombres más ilustres de la ciudad: el coronel de infantería, teniente coronel y comandante del Regimiento Fijo de la plaza, Agustín Lasssala, el coronel y comandante de las Milicias Disciplinadas, Luis Labussiere, el comandante del Real Cuerpo de Artillería, Eleuterio de Murga, el coronel y sargento mayor Gabriel Pérez, el auditor de guerra Juan Francisco Creagh, el secretario Alonso de Cangas Llanos y el ingeniero militar de origen argelino Felipe Ramírez, sucesor de Juan Francisco Mestre al abandonar este la isla el 28 de febrero de 1793 (AGMM, archidoc, 5606.8).

El objeto de esta reunión era informar al monarca y a la Junta Consultiva de Fortificación y Defensa de Indias del estado en el que se encontraba el sistema defensivo de la capital. En esta reunión se diseñó un complejo proyecto destinado a reforzar la defensa de la plaza, que fue aprobado por una real orden del 2I de abril de ese mismo año. En dicho proyecto se planteó la necesidad de construir ocho lanchas defendidas por un cañón de $24 \mathrm{~cm}$, dos chatas con cuatro cañones del calibre 8 cada una, cuatro lanchas parapetas con otros dos cañones del mismo

7 Según la RAE, una batería es una fortificación destinada a contener un número de piezas de artillería a cubierto, un fuerte es un recinto fortificado y un fortín es una de las obras que se levantan en los atrincheramientos de un ejército para su mayor defensa. 
calibre, seis obuses del calibre 24, seis del calibre 6 y cuatro bombarderas con un mortero del calibre I2, además de reforzar la defensa de la bahía y el puerto con un navío de guerra, dos fragatas y dos bergantines.

Se recomendó habilitar los buques mayores y menores del puerto armándolos con artillería y seis goletas de comercio, armadas con uno o dos cañones cada una; reforzar la guarnición de la plaza, que en ese momento solamente contaba con 1056 hombres, y realizar varias obras de mejora en algunas defensas como las baterías de Santa Bárbara y el Carmen en el castillo de San Felipe del Morro y el fuerte de La Princesa del castillo de San Cristóbal, tras un reconocimiento llevado a cabo por Felipe Ramírez a todas las defensas de la ciudad (AGMM, archidoc, 5606.8; AGS, sGU, leg. 7I48,48). Sin embargo, la aportación más relevante de este documento es que permite constatar que la batería de San Francisco de Paula ya existía en ese momento y se encontraba en muy mal estado de conservación.

Por tanto, la fecha de construcción conocida hasta ahora no es la correcta. No se ha podido localizar hasta el momento ninguna fuente gráfica ni documental que permita fijar la fecha exacta de su edificación, aunque un plano trazado por el ingeniero jefe de las Reales Obras de Fortificación, Juan Francisco Mestre, fechado el I3 de septiembre de 1783 , muestra que el fuerte ya existía en ese momento (figura I). Por ello, es posible pensar que esta batería fuera ejecutada en torno al año I783, momento en el que Mestre reforzó el sistema defensivo de la ciudad y propuso construir varias baterías provisionales en las inmediaciones del fuerte de San Jerónimo del Boquerón.

Otras fuentes gráficas y documentales del Archivo General de Indias y del Archivo General Militar de Madrid certifican que fue una batería provisional de tierra y fajina erigida entre los baluartes de San Pedro y Santiago (figura 2), cuya finalidad era reforzar la defensa de la costa sureste de la ciudad, evitar el envite de las olas en el recinto amurallado de este sector y dificultar el acceso de posibles lanchas enemigas a la laguna de Condado y al caño de San Antonio, defendido por el fuerte de San Jerónimo del Boquerón, y a las inmediaciones de la isla de Miraflores (AGI, Santo_Domingo, 2315). 


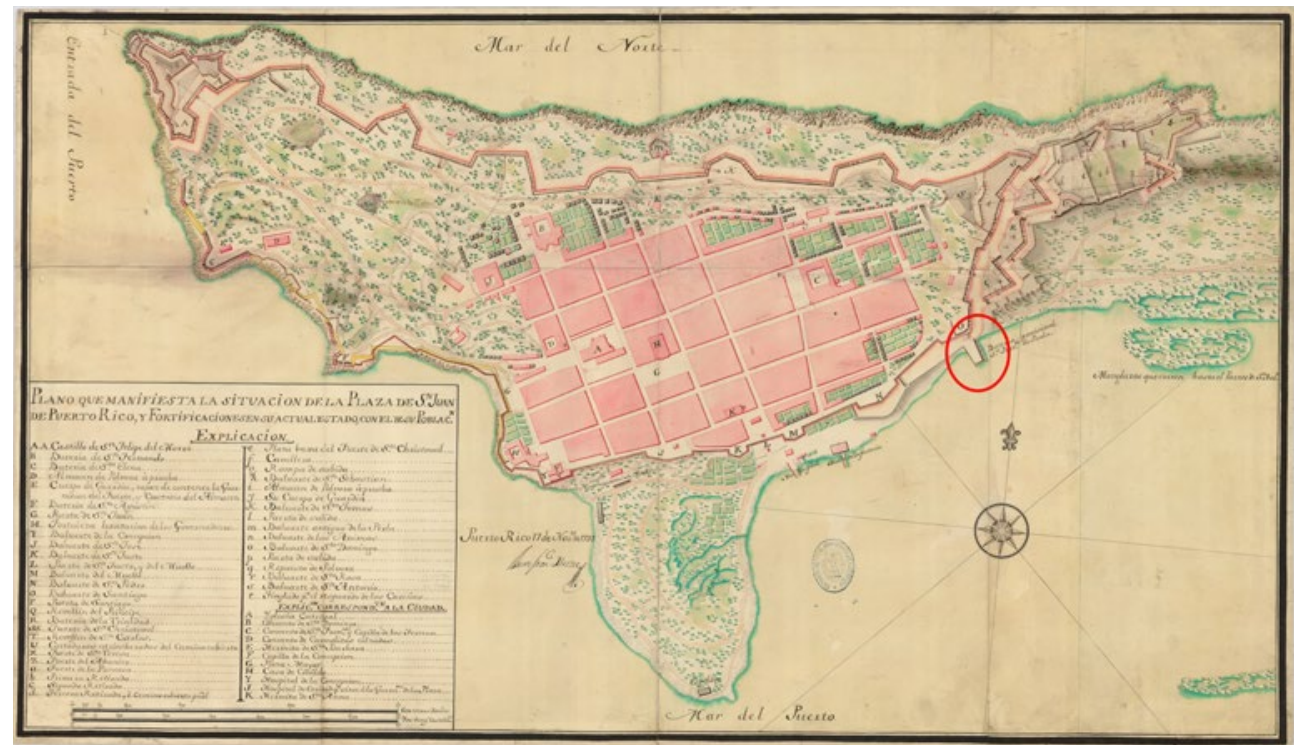

$\rightarrow$ FIGURA I.

"Plano de la plaza de Puerto Rico y sus inmediaciones"

Fuente: AGMM, PRI-I5/9.

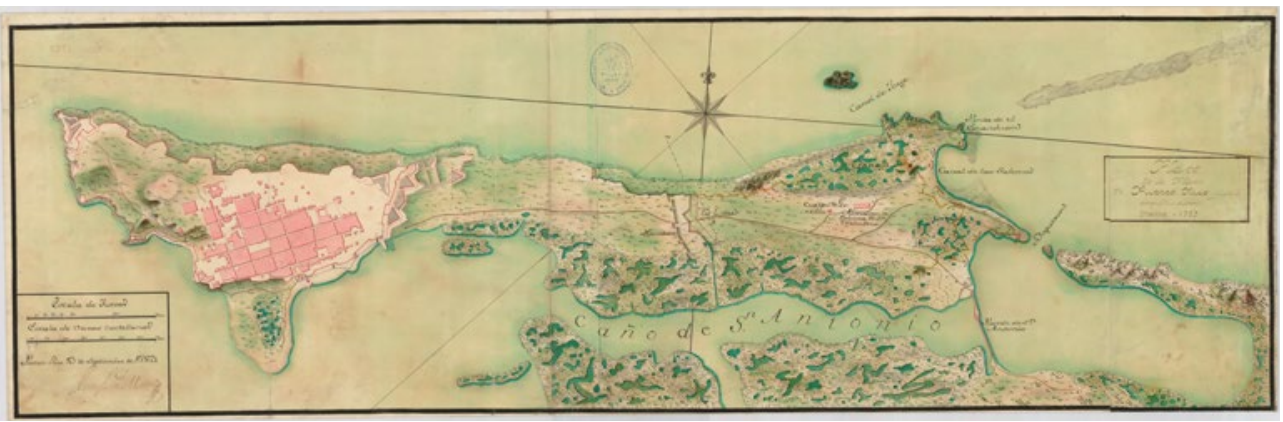

$\leftrightarrow$ FIGURA 2.

"Plano que manifiesta la situacion de la plaza de Sn. Juan de Puerto Rico, y fortificaciones en su actual estado, con el de su poblacn"

Fuente: AGMM, cartoteca, PRI-I5/7.

Un informe elaborado por el ingeniero Felipe Ramírez describe la batería de San Francisco de Paula como un espigón de tierra y fajina, y plantea la necesidad de convertir esta fortificación en una defensa permanente, para evitar el continuo envite del mar en las cortinas del lado sur de la capital (AGMM, archidoc, 5606.8). Además, varios documentos firmados por este ingeniero militar, localizados en el Archivo General de Indias, desconocidos hasta la fecha, 
muestran que esta batería fue reparada en varias ocasiones entre 1795 y 1796 (AGI, Santo_Domingo, 23I5). Felipe Ramírez propuso construir un malecón y reforzar la defensa de esta fortificación mediante la construcción de un foso y la ampliación de varias piezas de artillería, cuyos costes ascendieron, a finales de junio de 1796 , a un importe de 5823 pesos, 5 reales y 19 maravedís.

Estas no fueron las únicas modificaciones realizadas en su fábrica, puesto que, según consta en varios presupuestos, durante los meses de julio y agosto se hicieron nuevas reparaciones valoradas en 184 pesos y 7 reales, aunque se desconoce en qué consistieron dichas obras, debido a que no aparecen mencionadas en ninguno de los documentos analizados para este estudio (AGI, Santo_Domingo, 2315). Según consta en la Revista de España, de Indias y del Extranjero, en el mes de noviembre de 1796, el gobernador Ramón de Castro dispuso el aumento de la guarnición de esta batería y una buena dotación de artillería, por considerar que esta fortificación era un punto fundamental para la defensa de la ciudad de San Juan (Gonzalo y Carbonell 295).

En la obra Lealtad y heroismo de la isla de Puerto Rico 1797-1897, publicada en 1897, se afirma que el teniente coronel Federico García de Saint Just, natural de la ciudad de Aviñón (Francia), trabajó al servicio de la Corona española en la isla durante tres años y cinco meses y fue el encargado de defender esta fortificación durante el ataque británico ocurrido en 1797, al mando del general sir Ralph Abercombry, aunque no se ha podido encontrar ningún documento que permita constatar esta información (Lealtad I42).

\section{Obras de mejora y reparación realizadas en la batería durante el siglo decimonónico}

Algunos planos trazados durante las dos últimas décadas del siglo XVIII por el ingeniero Juan Francisco Mestre, así como varias cartas náuticas levantadas por el capitán de navío de la Real Armada Cosme Damián Churruca, permiten analizar con el detenimiento que su importancia requiere, la construcción de las defensas y la importante labor de ingeniería llevada a cabo por el Real Cuerpo de Ingenieros en la isla durante el periodo colonial, aunque ninguna de estas fuentes gráficas muestra las características arquitectónicas de dicha obra defensiva. Sin embargo, un plano firmado por el comandante de ingenieros Rafael Aguirre el 4 de marzo de I893, supervisado y aprobado por el ingeniero general Manuel Cortés y Agulló, hasta el momento desconocido, permite constatar que la batería 
de San Francisco de Paula fue una fortificación muy similar al fuerte de San Jerónimo del Boquerón (figura 3).

Fue una construcción de mampostería con cubierta de azotea y planta irregular erigida dentro del mar, cuyas dimensiones eran: aproximadamente $39 \mathrm{~m}$ de largo en el parapeto oeste, $47 \mathrm{~m}$ el muro paralelo, 32,63 m la cortina que unía el fuerte con el muelle, mediante un puente de mampostería de dos arcos que facilitaba el acceso a esta fortificación, y unos 33 metros de largo en la diagonal sur. Su defensa se reforzó con la construcción de un camino cubierto, una garita de planta circular y cuatro troneras dotadas de varias piezas de artillería que dificultaban un posible asalto e impedían la llegada de lanchas enemigas a las cortinas del sector sureste de la ciudad.

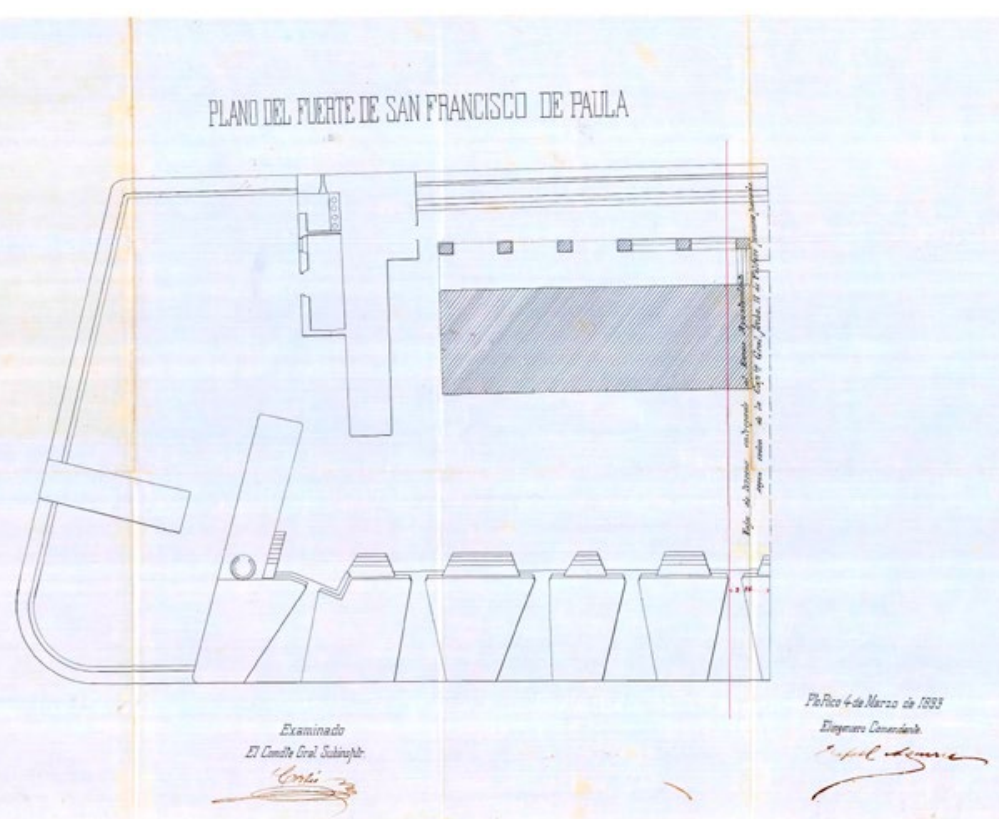

a FIGURA 3 .

"Plano del fuerte de San Francisco de Paula"

Fuente: AGMM, PRI-32/20.

Las características arquitectónicas de esta batería presentan gran similitud con el fuerte de San Jerónimo del Boquerón (figura 4), un pequeño fortín de madera de planta cuadrada erigido sobre un peñasco de roca arenisca en la punta de Cangrejos, a unos I5 $\mathrm{km}$ al este de la capital, cuya finalidad era evitar el paso 
de posibles lanchas enemigas a la laguna de Condado y a las inmediaciones del caño y el puente de San Antonio. La mayoría de los expertos que mencionan esta fortificación datan su construcción hacia el año 1587 y consideran que debió de tener capacidad para alojar hasta ocho piezas de artillería, aunque no se ha podido localizar hasta el momento ninguna fuente gráfica ni documental que permita corroborar esta información, o bien conocer la guarnición encargada de su defensa (Alegría 173; Negroni 179).

Este fortín fue de vital importancia durante el ataque sufrido en la isla en I595 por el pirata sir Francis Drake, ya que el objetivo de las tropas británicas era desembarcar en la punta de Cangrejos y avanzar hacia la capital, lo cual hizo que el fuerte quedara prácticamente arruinado tras el combate y fuera reconstruido en piedra a comienzos del siglo XVII, momento en el que se convirtió en el castillo de San Jerónimo del Boquerón (figura 5$)^{8}$.

A comienzos del siglo xix se llevaron a cabo varias obras de mejora en las inmediaciones de la batería de San Francisco de Paula, puesto que el gobernador y capitán general de la isla, Toribio de Montes, vio la necesidad de invertir importantes recursos en la construcción de nuevas obras públicas y el trazado de caminos y carreteras, para facilitar la conexión de la capital con el resto de la isla. En enero de 1836 se planteó la necesidad de reemplazar el primitivo muelle como consecuencia de su mal estado de conservación y se proyectaron varias obras de mejora en los puentes de San Antonio y Martín Peña valoradas en I 000 pesos, que fueron costeadas con un arancel impuesto el 3I de julio de I835 sobre la producción de aguardiente (AGMM, archidoc, 5633.I).

Estas reparaciones las dirigió el comandante de ingenieros Santiago Cortijo, quien informó a la Junta de Comercio y Fomento de la isla de que la construcción del nuevo muelle se prolongaría durante un plazo aproximado de dieciocho a veinticuatro meses. El ingeniero solicitó un sueldo de Ioo pesos mensuales y una recompensa económica tras la adquisición del material y la maquinaria empleada en su construcción, y entre I840 y I84I realizó nuevas obras de ampliación, debido a que el muelle original solamente tenía capacidad para dos buques.

8 A muy pocos metros de distancia del fuerte de San Jerónimo del Boquerón se levantó la batería del Escambrón, en la punta conocida como Cabrón, Cambrón o Escambrón. Fue una pequeña obra defensiva realizada en mampostería, destinada a reforzar la defensa del fuerte del Boquerón y neutralizar posibles desembarcos enemigos en este sector (Zapatero, "El periodo de esplendor" 45). 


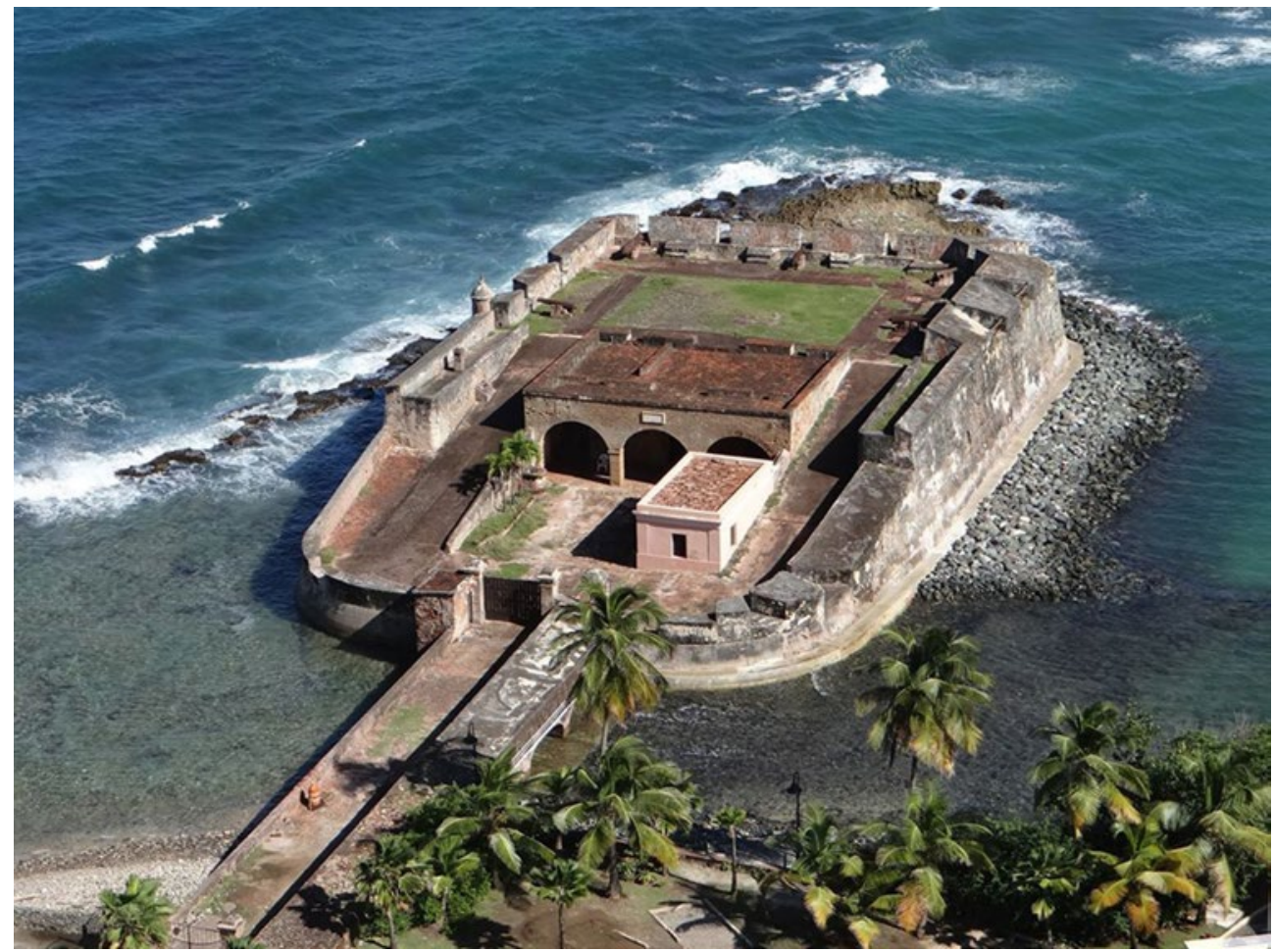

- FIGURA 4 .

Fuerte de San Jerónimo del Boquerón

Fuente: fotografía de la autora.

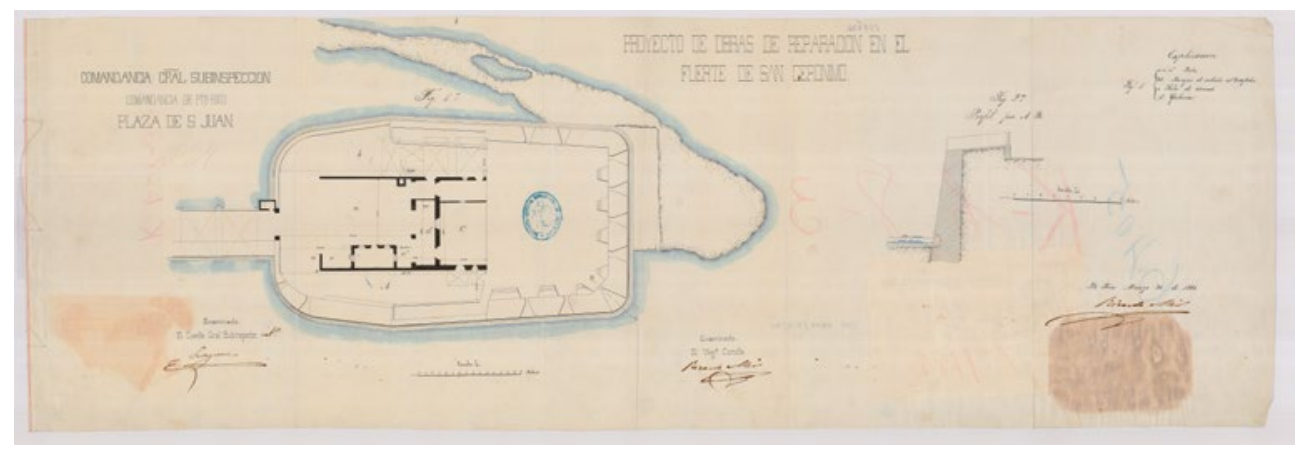

$\rightarrow$ FIGURA 5 .

Proyecto de obras de reparación en el fuerte de San Gerónimo

Fuente: AGMM, PRI-I7/I2. 
Tres décadas después, concretamente en noviembre de i87i, se hicieron nuevas obras de mejora destinadas a prolongar el muelle desde el edificio de la Aduana hasta la batería de San Francisco de Paula, con el objetivo de desarrollar el comercio de la isla y facilitar la adquisición de locales que más tarde fueron convertidos en almacenes y depósitos de mercancías. Ello obligó a construir varios edificios de madera y mampostería cubiertos con teja o azotea, y la Junta de Fortificaciones y Defensa de Indias determinó la imposibilidad de que dichas construcciones excedieran los 5,5 $\mathrm{m}$ de altura, para que no impidieran la normal utilización y eficacia de la artillería (AHN, ultramar, 355).

Este proyecto fue acompañado de un plano firmado por el ingeniero de Obras Públicas Evaristo Churruca el i9 de octubre de I87I, en el que aparecen representados todos los solares y las propiedades del muelle, los cuales tenían diversas proporciones que variaban desde los $2333 \mathrm{~m}$ de la casa Latimer hasta los IOI $\mathrm{m}$ de alguna casa particular. Esta fuente gráfica certifica, además, que la forma de este sector de la ciudad impedía llevar a cabo una distribución regular de las calles y los solares, teniendo en cuenta que estos últimos daban al muelle y fueron trazados de forma paralela hasta el almacén de la Aduana. La vía principal medía unos $12 \mathrm{~m}$ de ancho, ya que el objetivo principal era facilitar el tránsito del público y el acarreo de las carretas que llegaban al muelle para cargar los convoyes de azúcar.

Estas características obligaron a Churruca a proponer una ampliación de las dimensiones de la Aduana; consideró la necesidad de dejar para el tránsito público el barracón de madera utilizado como depósito de duelas y otros materiales de tonelería de D. Ramón Fernández y adquirir el solar del Sr. Peralti, situado junto a los de la familia Latimer, Arana y Caracena, para facilitar el tránsito de las carretas que entraban al muelle desde el tinglado cubierto y el almacén del Sr. Peralti, ya que este era el único paso que llegaba a la Aduana. Proyectó un segundo paso público entre los solares de Arana y Caracena, por ser este último el que daba frente al muelle, ya que tras él había un gran número de almacenes y casas particulares de madera, cuyos solares confrontaban con el mar. Estos aparecen limitados en el plano con una línea quebrada trazada a una pequeńa distancia del mar, pues en esta parte desembocaban dos de las principales alcantarillas de la ciudad.

El ingeniero propuso además abrir una puerta en la calle Tanca para facilitar la comunicación intramuros de San Juan, por considerar que la puerta de San Juan no era suficiente. Además, varios documentos localizados en el Archivo Histórico Nacional de Madrid certifican que en una sesión celebrada 
el 28 de junio de I893, el gobernador y capitán general de la isla, Antonio Dabán y Ramírez de Arellano, autorizó la venta de los terrenos comprendidos entre el extremo oriental del muelle este y la batería de San Francisco de Paula, como también la venta de solares del barrio de La Carbonera, adyacente a esta fortificación, tras el dragado en el que se le ganaron $2000 \mathrm{~m}^{2}$ al mar en este sector (AHN, ultramar, 407) (figura 6).

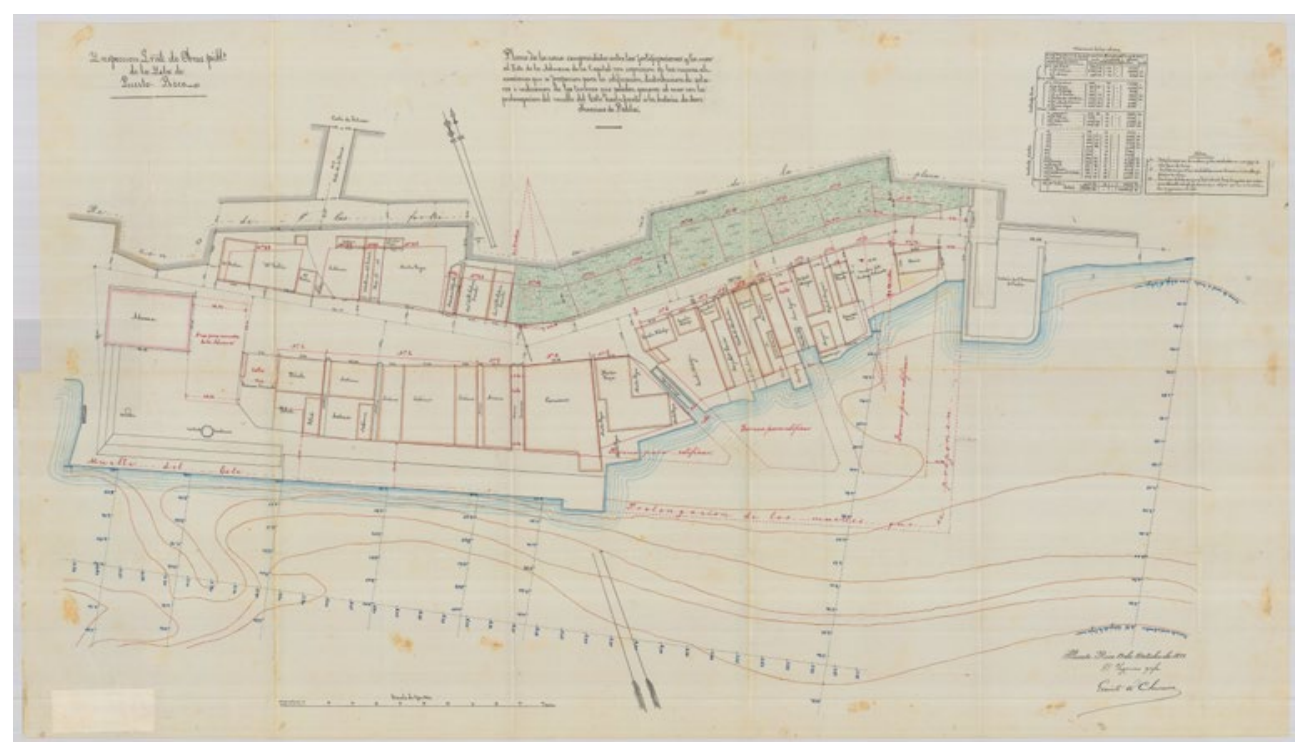

$\rightarrow$ FIGURA 6.

"Plano de la zona comprendida entre las fortificaciones y la mar del Este de la Aduana de la capital con expresión de las nuevas alineaciones que se proponen para la edificación, distribución de solares e indicación de los terrenos que pueden ganarse al mar con la prolongación del muelle del Este hasta el frente a la batería de San Francisco de Paula"

Fuente: AGMM, cartoteca, PRI-52/20.

Tras un reconocimiento realizado a las defensas de la ciudad el 27 de febrero de 1859, Santiago Cortijo informó de la necesidad de realizar varias obras de mejora en la batería de San Francisco de Paula, debido al mal estado de conservación en el que se encontraban sus cimientos como consecuencia del continuo envite del oleaje. El ingeniero propuso reforzar la defensa de la batería con un revestimiento de mortero hidráulico y planteó la necesidad de reparar el pavimento del patio y todas las estancias del fuerte; reedificar los alojamientos de la tropa y reemplazar los traveses de la batería (AGMm, Colección General de Documentos, 4-I-8-5). 
Otro documento localizado en el Archivo General de Puerto Rico permite constatar que el 29 de agosto de 1879 se propuso derribar una de sus troneras, así como parte del parapeto oriental de la batería, para recalzar el terreno inmediato a esta fortificación, con el fin de evitar posibles accidentes (AGPR, FDMSJSCC, caja 36).

El 24 de marzo de I886, el teniente de ingenieros José Laguna propuso transformar los cuerpos de guardia de los baluartes de San Agustín, San José y la batería de San Francisco de Paula, además de un barracón de madera emplazado en el área Puerta de Tierra — situado a extramuros de la capital—, en pabellones para jefes y oficiales de la guarnición de la plaza, dotados de cubierta de azoteas. Para ello, propuso la utilización de vigas y carriles acanalados de desecho de un tranvía, cuyos costes fueron valorados en 3970 pesos. Sin embargo, es posible pensar que las obras no fueran ejecutadas en ese momento, puesto que el $4 \mathrm{de}$ agosto de ese mismo año, el ingeniero insistía en la necesidad de construir un cuerpo de guardia sencillo y austero para aumentar la guarnición encargada de la defensa de esta fortificación. Así, diseñó un edificio de planta rectangular de 19 x 9 m, con pavimento de madera, dotado de varios vanos para facilitar la ventilación e iluminación de las estancias, cuyos costes estimó en 730 pesos.

Es posible que el edificio no fuera construido hasta una década más tarde, puesto que el 27 de mayo de 1895 el capitán de ingenieros Pedro de Pastor — de quien no hemos podido localizar hasta el momento su hoja de servicios militares ni su expediente personal- diseñó un nuevo proyecto en el que planteó la construcción de un cuerpo de guardia capaz de alojar hasta veinte soldados. Este proyecto fue acompañado de un plano manuscrito de 67,8 x II6,I cm, realizado con plumilla en tinta negra, roja y azul, en el que aparece representada la planta de la batería, alzado de una de las fachadas del edificio, pendientes de la azotea, un perfil transversal de su fábrica y el detalle de la bisagra de un portón, con las dimensiones de cada una de las figuras (figura 7). Según consta en dicho plano, este proyecto fue aprobado por el monarca el 8 de junio de I895 tras recibir el visto bueno del comandante de ingenieros Ángel María Rosell y el comandante general y subinspector del Real Cuerpo de Ingenieros de la plaza, José Laguna (AGMM, archidoc, 5631.4).

Otro plano manuscrito, elaborado en plumilla con tinta negra, azul y amarilla, de 68 x I2I, $5 \mathrm{~cm}$, que se encuentra en el mismo archivo, también desconocido hasta la fecha, certifica que el 4 de abril de 1895 el ingeniero Francisco José Cañizares proyectó la construcción de un horno de $4 \mathrm{~m}$ de diámetro en el interior de la batería, cuyas obras fueron aprobadas por el monarca el 8 de junio de ese mismo año (figura 8). Esta fuente gráfica muestra la planta de la batería 


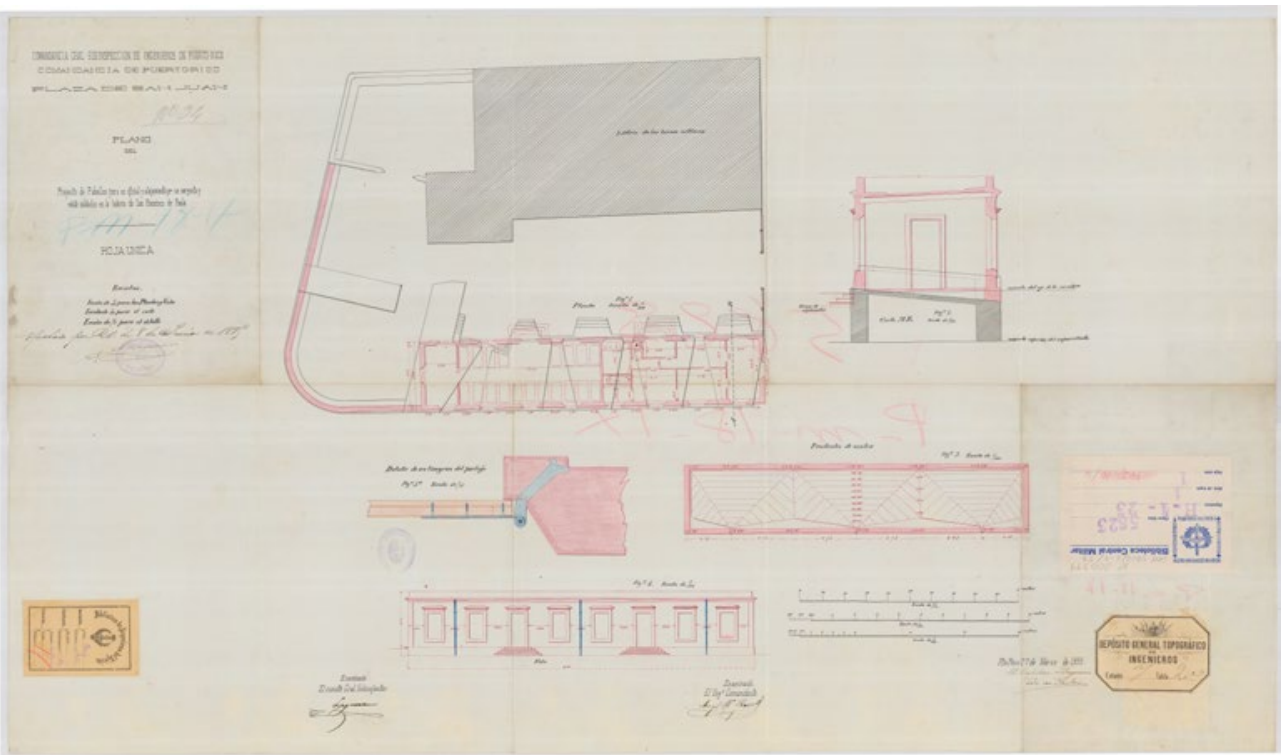

$\leftrightarrow$ FIGURA 7.

"Plano del Proyecto del Pabellón para un oficial y alojamiento pa. un sargento y veinte soldados en la bateria de San Francisco de Paula: Hoja Única"

Fuente: AGMM, cartoteca, PRI-IO/4.

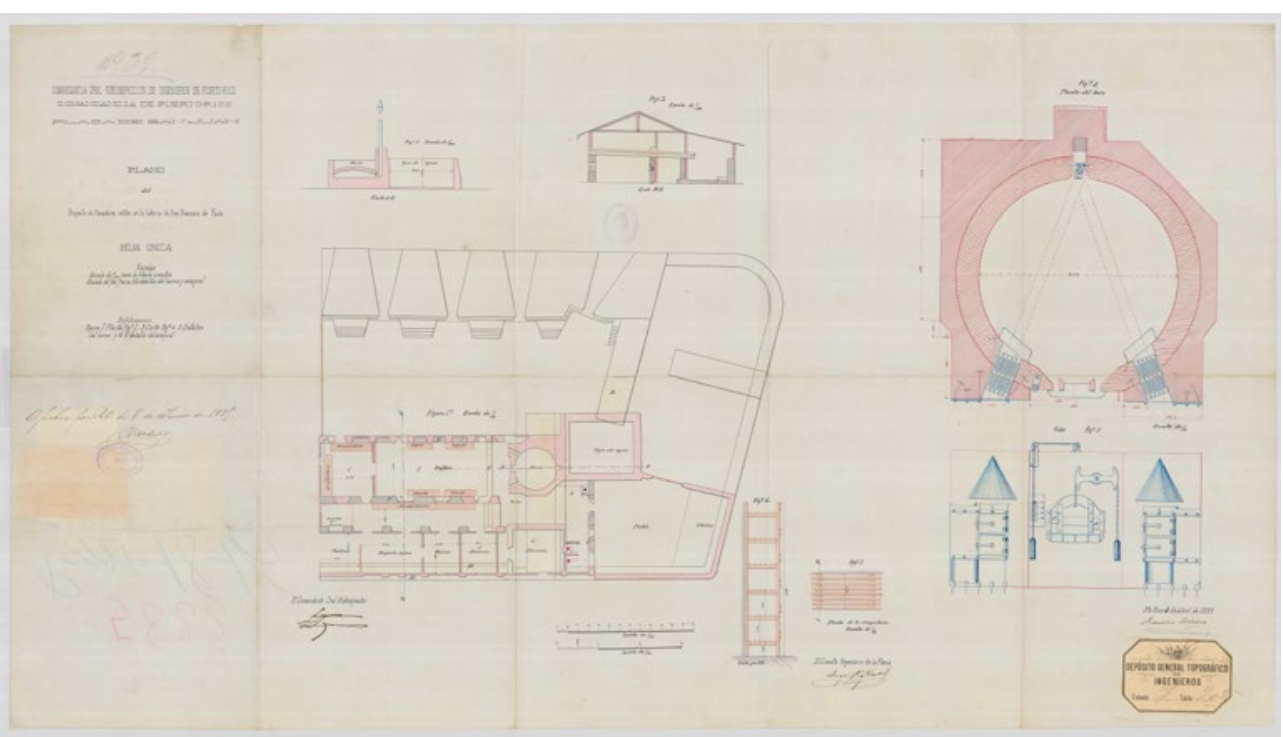

$\rightarrow$ FIGURA 8.

"Plano del proyecto de panadería militar en la batería de San Francisco de Paula"

Fuente: AGMM, cartoteca, PRI-IO/5. 
de San Francisco de Paula y varias plantas, alzados, perfiles y detalles del horno proyectado, y permite constatar que el horno contaba con varios almacenes dotados de anaqueles o estantes de madera, varios vestíbulos, amasadoras, patios, oficinas, un despacho de pan, taller, aljibe y un depósito de harina.

En I895, José Laguna proyectó la construcción de una batería en el alto del Olimpo, situado en el área de Santurce, y la batería de Santa Ana en el alto del mismo nombre, con el fin de reforzar la defensa del fuerte de San Jerónimo del Boquerón, las baterías del Escambrón, Santo Toribio, San Francisco de Paula, el fuerte de El Cañuelo, la isla de Miraflores y los puentes de Martín Peña y San Antonio, ante la posibilidad de un inminente ataque (AGMM, archidoc, 56I2.2). Es posible pensar que la batería de San Francisco de Paula desapareciera dos años después, puesto que el 28 de abril de 1897 se aprobó la demolición de las cortinas y algunas defensas del lado sur y este de la ciudad, situadas entre el castillo de San Cristóbal y el baluarte de Santiago, la media luna, el camino cubierto y el foso, la plaza de armas de La Trinidad, el revellín, la puerta de Santiago y el lienzo de muralla ubicado entre el baluarte de San Justo y San Pedro Mártir.

La demolición comenzó a las nueve de la mañana del 17 de mayo de ese mismo año, sus costes fueron sufragados por el Ayuntamiento de la ciudad de San Juan. Varios informes elaborados con motivo del derribo de estas defensas indican que la batería de San Francisco de Paula sobresalía de la línea costera de la bahía, emplazamiento que fue rellanado para desarrollar la zona portuaria. En la actualidad, todavía pueden apreciarse algunos restos de los cimientos de esta fortificación en las inmediaciones de una sucursal del Banco Popular, situada en la calle Nilita Vientos Gastón, muy próxima al paseo de Covadonga, cuyas coordenadas geográficas son I8 $27^{\prime} 53.70^{\prime \prime} \mathrm{N} \mathrm{y} 66^{\circ} 6^{\prime} 4 \mathrm{I}, 5^{\prime}$ "W (figuras 9 y IO).

El último dato que se conoce de esta obra defensiva es que el cuerpo de guardia fue entregado por el comandante de ingenieros Eduardo González al comisario de los Estados Unidos, Alberto Belenguer, el I8 de octubre de I898. El documento referido permite constatar que el cuerpo de guardia medía I $326 \mathrm{~m}^{2}$, tenía una capacidad cúbica de $2463,32 \mathrm{~m}^{3}$, la panadería militar tenía una superficie cubierta de $615 \mathrm{~m}^{2}$, puesto que el resto era patio, y fue tasada en 13000 pesos (AGMM, archidoc, 5627.5). 

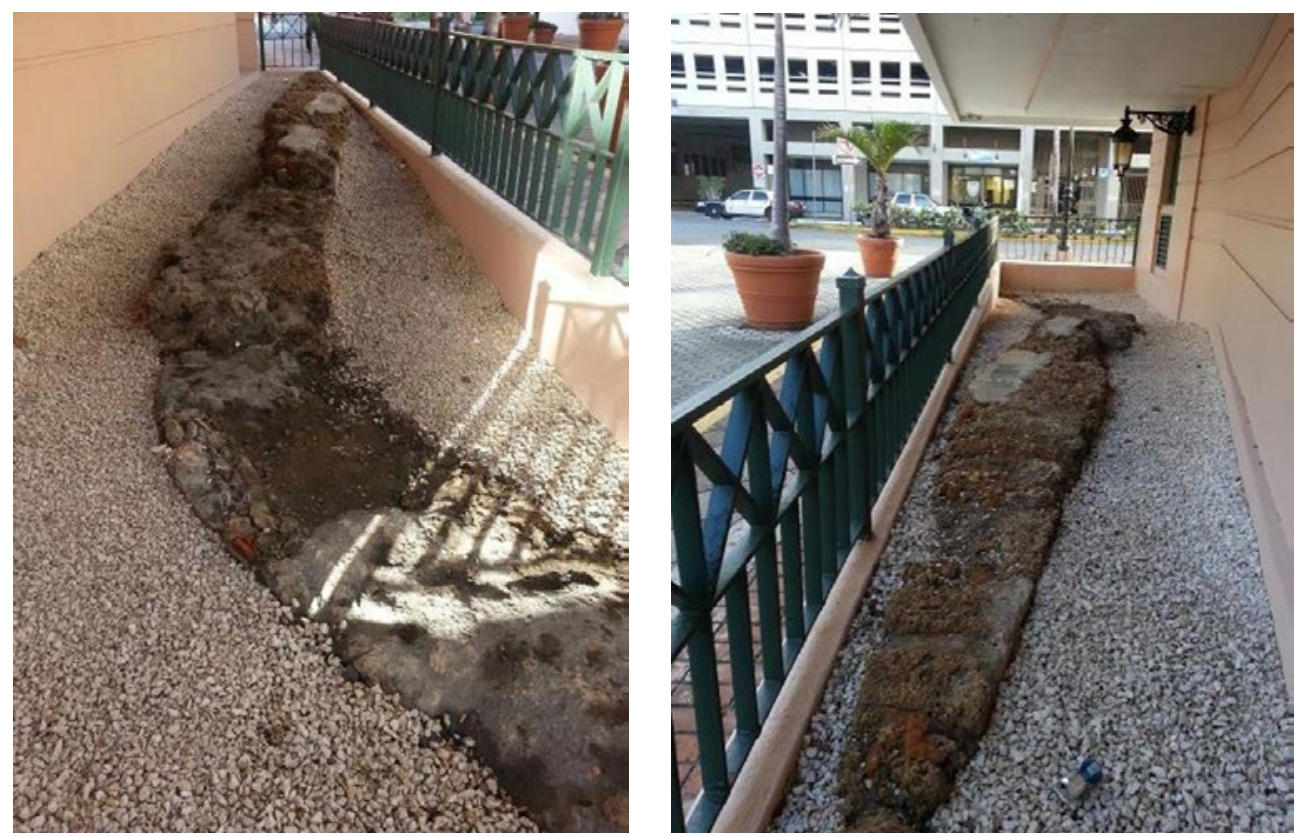

$\rightarrow$ FIGURAS 9 Y IO.

Restos de la batería de San Francisco de Paula

Fuente: fotografías de la autora.

\section{Conclusión}

La batería de San Francisco de Paula, el fuerte de La Perla — construido a mediados del siglo XVII en el lado norte de la ciudad de San Juan-, o el fuerte del Olimpo, erigido en el área de Santurce, entre otras, son algunas las fortificaciones menos conocidas del sistema de defensas construido en la ciudad de San Juan desde su fundación a mediados del siglo Xvi. Esta fortificación ha sido considerada superficialmente por algunos de los expertos que analizaron las defensas de la ciudad, y la mayoría de ellos data su construcción en el año I796, pero ninguno analiza el modelo arquitectónico empleado en su fábrica.

Sin embargo, el análisis de varias fuentes gráficas y documentales custodiadas en el Archivo General Militar de Madrid, en el Archivo Histórico Nacional y en el Archivo General de Puerto Rico permite constatar que la fecha de construcción aportada hasta el momento no es la correcta, puesto que la batería de San Francisco de Paula fue construida por el ingeniero militar de origen extremeño Juan Francisco Mestre en torno al año I783, momento en el que elaboró un proyecto defensivo con el objetivo de convertir a la ciudad de San Juan en 
una plaza inexpugnable. Las fuentes gráficas analizadas para este estudio han sido fundamentales para conocer las características arquitectónicas empleadas en su fábrica, así como las obras de mejora y reparación realizadas en ella durante los siglos posteriores, como consecuencia de la evolución experimentada por la artillería con la aparición de los cañones de ánima rayada, las novedades tácticoestratégicas surgidas en el arte de la guerra y el estado ruinoso en el que se encontraba el sistema defensivo de la ciudad a mediados del siglo xix. Los informes elaborados por los ingenieros que trabajaron al servicio de la Corona española en la isla permiten analizar la evolución experimentada en esta fortificación, las dimensiones de su fábrica, el cuerpo de guardia construido para albergar a la tropa encargada de su defensa y el horno militar proyectado a finales del siglo xix para abastecer de alimentos como el pan o el bizcocho a la guarnición encargada de la defensa de la plaza de San Juan, ya que junto a otros víveres como galletas, carne salada, tocino, arroz, garbanzos, habichuelas y frijoles, entre otros, eran la base de la alimentación de la tropa española en Puerto Rico.

\section{6}

\section{B I B L I O G R A F í A}

\section{F U E N T ESPR I M A I A S}

Archivo General de Indias, Sevilla, España (AGI).

Cartas, expedientes y duplicados de gobernadores, sig. Santo_Domingo, 2310.

Cartas, expedientes y duplicados de gobernadores, sig. Santo_Domingo, 2304, 2308, 2315.

Fortificaciones, pertrechos de guerra y situados de tropa, sig. Santo_Domingo, 2510.

Licencia real otorgada a O'Daly para viajar a Puerto Rico, Sección de Contratación, sig. 5505, n. $^{\circ}$, ramo 32.

Archivo General de Puerto Rico, San Juan, Puerto Rico (AGPR).

Fondos Documentos Municipales de San Juan, Serie Calles y Caminos (FDMSJSCC) "Expediente relativo para solicitar del Exmo. Sr. Gobernador General, el derribo de la primera tronera del fuerte de San Francisco de Paula y la parte este la batería que está frente a la carretera", caja 36. 


\section{Archivo General de Simancas, Simancas, España (AGS).}

"Defensa de Puerto Rico", sig. SEG, leg. 7148,48.

"Hoja de Servicios Militares de Juan Francisco Mestre", sig. SGU, leg. 3793, caja 2, f. 69; SGU, leg. 5837, caja I, f. 37; sGU, leg. 5837, caja 2, f. 26 ; sGU, leg. 5837 , caja 4 , f. I8; SGU, leg. 3794, caja I, f. 6; sGU, leg. 5837, caja 5, f. I3.

Reemplazo y empleos de varios ingenieros, sig. SGU, leg. I239,30.

\section{Archivo General Militar de Madrid, Madrid, España (AgMM).}

"Propuesta para mejorar la defensa de Puerto Rico", archidoc, 5606.8.

"Fijación de las bases para el proyecto de nuevas defensas de Puerto Rico", archidoc, 5612.2.

"Edificios de guerra entregados a los americanos al evacuar el ejército español la isla de Puerto Rico", archidoc, 5627.5.

"Construcción y habilitación de pabellones en los cuerpos de guardia de San Juan de Puerto Rico", archidoc, 5631.4.

“Obras realizadas en el muelle de San Juan de Puerto Rico", archidoc, 5633.I.

"Parte de la revista pasada en el año i858 en la isla de Puerto Rico", Colección General de Documentos, 4-I-8-5

"Plano de la plaza de Puerto Rico y sus inmediaciones", Cartoteca, PRI-I5/9.

"Plano que manifiesta la situacion de la plaza de Sn. Juan de Puerto Rico, y fortificaciones en su actual estado, con el de su poblacn”, cartoteca, PRI-I5/7.

"Plano del fuerte de San Francisco de Paula", Cartoteca, PRI-32/20.

"Plano del Proyecto del Pabellón para un oficial y alojamiento pa. un sargento y veinte soldados en la bateria de San Francisco de Paula : Hoja Unica”, cartoteca, PRI-IO/4.

"Plano de la zona comprendida entre las fortificaciones y la mar del Este de la Aduana de la capital con expresión de las nuevas alineaciones que se proponen para la edificación, distribución de solares e indicación de los terrenos que pueden ganarse al mar con la prolongación del muelle del Este hasta el frente a la batería de San Francisco de Paula", cartoteca, PRI-52/20.

Archivo General Militar de Segovia, Segovia, España (AGMS).

"Expediente matrimonial de O'Daly", sig. I.\%/O-97.

"Expediente matrimonial de Juan Francisco Mestre”, sig. I.²/M-3057.

Archivo Histórico Nacional, Madrid, España (AHN).

"Expediente general sobre habilitación del puerto de San Juan”, ultramar, 407, exp. 47.

"Proyecto de edificación y distribución de solares de San Juan", ultramar, 355, exp. 2. 


\section{I F U E N T ESSECUNDARIA S}

Alegría, Ricardo E. El Fuerte de San Jerónimo del Boquerón. San Juan: Instituto de Cultura Puertorriqueña, 1969 .

Alonso, María Mercedes y Milagros Flores Román. El Caribe en el siglo XVIII y el ataque británico al puerto de Puerto Rico en I797. Puerto Rico: Publicaciones Puertorriqueñas, 1998.

Angulo Iñiguez, Diego. Bautista Antonelli. Las fortificaciones americanas del siglo XVI. Madrid: Editorial Hauser y Menet, 1942.

Blanes Martín, Tamara. "Caracterización tipológica de las fortificaciones coloniales del Caribe español". Revista Dana, n. ${ }^{\circ}$ 28-29, 1989-1990, pp. 62-73.

Capel, Horacio, Lurdes García i Lanceta, José Omar Moncada, Francesc Olivé, Santiago Quesada Casajuana, Antonio Rodríguez, Joan-Eugeni Sánchez y Rosa Tello. Los ingenieros militares en España. Siglo XVIII. Repertorio biográfico e inventario de su labor cientifica y espacial. Barcelona: Universidad de Barcelona, 1983.

Castro, María de los Ángeles. Arquitectura y urbanismo en San Juan de Puerto Rico (siglo $X I X)$. Tesis doctoral de la Universidad Complutense de Madrid, I976. San Juan: Universidad de Puerto Rico, Recinto de Río Piedras, 1980.

---. "La fortaleza de Santa Catalina. Apuntes para una historia de su arquitectura". Cuadernos de la Facultad de Humanidades, n. ${ }^{\circ}$, 1979, pp. $25-52$.

Córdova, Pedro Tomás. Memorias gráficas, históricas, económicas y estadísticas de la isla de Puerto Rico. Tomo III. San Juan: Oficina del Gobierno de Puerto Rico, 1832.

Cruz de Arrigoitia, José F. El situado mexicano: origen y desarrollo en Puerto Rico durante los años de 1582 a I599. Río Piedras: Universidad de Puerto Rico, 1984.

Gonzalo Morón, Fermín e Ignacio de Ramón Carbonell, editores. Revista de España, de Indias y del Extranjero. Tomo x. Madrid: Imprenta de la Publicidad, 1847.

Hinarejos Martín, Nuria. "La batería de la Perla de San Juan de Puerto Rico”. Revista de Historia Militar, n. ${ }^{\circ}$ 125, 2019, pp. 39-78.

---. "Estado de las defensas de San Juan de Puerto Rico en 1762 . Informe y propuesta de Tomás O'Daly". Espacios y muros del barroco iberoamericano, editado por María de los Ángeles Fernández Valle, Carme López Calderón e Inmaculada Rodríguez Moya. Sevilla: Universidad Pablo de Olavide, 2019, pp. 173-190.

---. "El ingeniero Tomás O’Daly en Puerto Rico". Actas del Congreso Internacional América: cultura visual y relaciones artísticas, editado por Rafael López Guzmán, Yolanda Guasch Marí y Guadalupe Romero Sánchez. Granada: Universidad de Granada, 2015, pp. 43-50. 
---. "La intervención del ingeniero Juan Francisco Mestre en el sistema de defensas de San Juan de Puerto Rico". Iberoamérica en perspectiva artística. Transferencias culturales $y$ devocionales, editado por Inmaculada Rodríguez Moya, María de los Ángeles Fernández Valle y Carme López Calderón. Castelló de la Plana: Universidad Jaume I, 2016, pp. 57-72.

---. El sistema de defensas de Puerto Rico (I493-1898). Madrid: Ministerio de Defensa, 2020.

Hostos, Adolfo. Ciudad Murada (I53I-I898). La Habana: Editorial Lex, 1948.

Lealtad y heroismo de la isla de Puerto Rico 1797-1897. Puerto Rico: Imprenta de A. Lyun e hijos de Pérez Moris, 1987.

Marchena Fernández, Juan. "Financiación militar y situados". Actas del II Congreso Internacional de Historia Militar. Zaragoza, 1988, pp. 261-310.

Negroni, Héctor Andrés. Historia militar de Puerto Rico. Madrid: Sociedad Estatal Quinto Centenario, 1992.

Torres Ramírez, Bibiano. La isla de Puerto Rico. 1765-180o. San Juan de Puerto Rico: Instituto de Cultura Puertorriqueña, 1968.

Torres Reyes, Ricardo. "El mariscal O'Reilly y las defensas de San Juan. 1765-1777”. Revista Historia, n. ${ }^{\circ}{ }_{1}$, tomo 4 , pp. 3-37

Zapatero, Juan Manuel. "Las fortificaciones históricas de San Juan de Puerto Rico". Militaria. Revista de Cultura Militar, n. ${ }^{\circ}$ I, 1989, pp. 141-175

---. "El periodo de esplendor en las fortificaciones de San Juan de Puerto Rico". Índice Cultura Español, n. ${ }^{\circ}$ I, 1959, pp. 24-47.

---. "La plaza fortificada de San Juan de Puerto Rico". Revista del Instituto de Cultura Puertorriqueña, n. ${ }^{\circ} 32,1966$, pp. 60-64.

---. “San Juan de Puerto Rico, 'la perla' fortificada del Caribe”. Revista ASINTO, julio-diciembre, 1995, pp. 39-52.

--.. "Síntesis histórica de la fortificación abaluartada". Revista Historia Militar, n. ${ }^{\circ}$ 12, 1963 , pp. 85-109. 